\title{
The Influence of Permeability Variation in a Heterogeneous and Homogeneous Reservoir during Polymer Flooding
}

\author{
Bright Bariakpoa Kinate*, Kingdom Onyemuche Choko, Adaobi Stephenie Nwosi-Anele \\ Department of Petroleum Engineering, Faculty of Engineering, Rivers State University, Nigeria
}

*Corresponding Author: Bright Bariakpoa Kinate, Department of Petroleum Engineering, Faculty of Engineering, Rivers State University, Nigeria

\begin{abstract}
This study examines the influence of permeability variations on the performance of polymer flooding in an enhanced oil recovery with the use of ECLIPSE simulator. A synthetic reservoir model (10x10x1) was constructed for two reservoir models, a heterogeneous system (Reservoir X-A) and a homogeneous system (Reservoir $X-B)$.Both cases were simulated at same reservoir conditions by polymer injection at a rate and concentration of 200STB/day and 50Lb/STB and analyzed at a time stepping of 10days over a 10years field life. The parameters analyzed were water relative permeability, oil relative permeability, oil-water capillary pressure, equivalent mixture viscosity, permeability reduction coefficient, block polymer adsorption, field pressure, field oil production rate and well flowing bottom hole pressure. Results revealed a fast reduction in the oil phase mobility for the heterogeneous system for high permeability above $25 \mathrm{md}$ and a water breakthrough for the producer in the homogeneous reservoir. Polymer adsorption rates in higher permeable zones are lower than the low permeable zone. The heterogeneous reservoir has the highest pressure decline while the homogeneous system has a better production rates. The influence of permeable channels is more pronounced in the injection well vicinity.
\end{abstract}

Keywords: Polymer, Flooding, Heterogeneous, Homogeneous, Permeability, Channels, Relative Permeability, Oil-Water, Capillary Pressure, Mobility.

\section{INTRODUCTION}

Rock properties variation with their location in the reservoir is an important consideration in fluid flow characterization. Reservoirs with strong heterogeneity usually have a fast decline in the formation pressure when naturally driven [1,2].The use of pressure maintenance schemes such as water or gas injection is a global practice employed in fields to boost the pressure to enhance flow of fluid. Water or gas injection helps to revive the formation pressure of the reservoir within a short period of injection. However, the subsequent presence of high permeability streaks within the reservoir heterogeneity results in the formation of dominant channel after a long period of injection. This ultimately results to issues such as viscous fingering and area sweep inefficiency [3,4].Hence, it is necessary to plug the highly permeable channels where a dominant channel exist [5].The application of polymer flooding as an enhanced oil recovery(EOR) technology has superior advantage over normal water injection in terms of improved sweep efficiency and better mobility control[6-10]. Polymer flooding is very widely applied globally as an efficient EOR technique that dated back to over 40years with China currently leading in the polymer flooding EOR technology [11]. Several attempts have been made to study the contribution of certain physiochemical properties that characterizes the efficiency of polymer flooding to include viscosity, rheology, inaccessible pore volumes (IPVs), polymer adsorption and degradation [12-19].Knowledge of the extent of the influence of these parameters on the performance of polymer flooding is very integral to designing an efficient polymer EOR project. The underlying principle of EOR by polymer flooding is essentially based on water mobility alteration for more efficient volumetric sweep. This effect is more pronounced in heavy oil reservoirs where water phase mobility extremely high. In a very highly heterogeneous system, a preferred flow path (channel) often exist which facilitates increment in water phase mobility and subsequent bypassing of the oil bank [20]. This ultimately results to low oil recovery from the reservoir. However, with the application of polymers, there is incremental oil recovery that could be attributed to better volumetric sweep or microscopic sweep efficiency. The various field success stories associated with the polymer flooding EOR technology and the need to expand its scope of application has led to a wider spectrum of modifying polymer flooding schemes. 
This assertion and several other studies, and knowledge of empirical polymer science have shown that heterogeneity is a very important factor in the overall design, performance and analysis of any EOR polymer flooding project. Despite notable success stories with polymer flooding across the globe, it should be noted that it is relatively capital intensive and hence would require thorough and rigorous candidate screening to minimize failure risk [21,22]. Commercial reservoir simulation is an important tool that has been employed in the industries in screening, characterization and prediction of the initial performance of a waterflooding project in the presence of reservoir heterogeneity [23, 24]. In this study, a commercial reservoir simulator (Eclipse) is used to analyze the performance of case study Reservoir X-A and X-B. The analyses were focused on the influence of permeability variations in $\mathrm{X}$ and $\mathrm{Y}$ directions of the heterogeneous and homogeneous local grids.

\section{Methodology}

\subsection{Fundamental Mathematical Formulations}

The major fluid systems present in the reservoir undergoing polymer injection are oil, water and polymer solution. The mass conservation equation of each component can be written by applying Darcy equations as follows:

For oil;

$$
\nabla \cdot\left[\frac{\vec{k} k_{r o}}{\mu_{o} B_{O}}\left(\nabla P_{O}-\rho_{O} g \nabla Z\right)\right]+q_{o}=\frac{\partial}{\partial t}\left(\frac{\varnothing S_{o}}{B_{O}}\right)
$$

For water;

$\nabla \cdot\left[\frac{\vec{k} k_{r w}}{\mu_{w e} B_{w} R_{k}}\left(\nabla P_{w}-\rho_{w} g \nabla Z\right)\right]+q_{w}=\frac{\partial}{\partial t}\left(\frac{\emptyset S_{w}}{B_{w}}\right)$

For polymer component;

i. High molecular weight polymer

$\nabla \cdot\left[\frac{\vec{k} k_{r w} c_{h p}}{\mu_{w e} B_{w} R_{k}}\left(\nabla P_{w}-\rho_{w} g \nabla Z\right)\right]-c_{h p} R_{p d}+q_{w} c_{h p}=\frac{\partial}{\partial t}\left(\frac{\emptyset\left(1-f_{i p v}\right) s_{w} c_{h p}}{B_{w}}\right)+\frac{\partial}{\partial t}\left(\frac{(1-\emptyset)\left(1-f_{i p v}\right) \rho_{r} c_{h p a}}{B_{w}}\right)$

ii. Low molecular weight polymer

$$
\nabla \cdot\left[\frac{\vec{k} k_{r w} c_{l p}}{\mu_{w e} B_{w} R_{k}}\left(\nabla P_{w}-\rho_{w} g \nabla Z\right)\right]+c_{l p} R_{p d}+q_{w} c_{l p}=\frac{\partial}{\partial t}\left(\frac{\emptyset\left(1-f_{i p v}\right) S_{w} c_{l p}}{B_{w}}\right)+\frac{\partial}{\partial t}\left(\frac{(1-\varnothing)\left(1-f_{i p v}\right) \rho_{r} c_{l p a}}{B_{w}}\right)
$$

Where;

$\vec{k}=$ absolute permeability tensor $\left(\mu m^{2}\right), k_{r o}, k_{r w}=$ relative permeability to oil and water respectively, $\mu_{o}=$ oil viscosity (mPa-s), $\mu_{w e}=$ effective water viscosity $(\mathrm{mPa}-\mathrm{s}), B_{O}, B_{w}=$ oil and water FVF respectively $\left(\mathrm{m}^{3} / \mathrm{m}^{3}\right), \rho_{w}, \rho_{o}=$ water and oil densities respectively $\left(\mathrm{kg} / \mathrm{m}^{3}\right), \mathrm{Z}=$ vertical depth $(\mathrm{m})$, $q_{o}, q_{w}=$ oil and water flow rates respectively $\left(\mathrm{m}^{3} /\right.$ day), $\emptyset=$ porosity (fraction), $S_{o}, S_{w}=$ oil and water saturations respectively (fraction), $c_{p}=$ polymer concentration $\left(\mathrm{kg} / \mathrm{m}^{3}\right), f_{i p v}=$ inaccessible pore volume factor, $\rho_{r}=$ rock density $\left(\mathrm{kg} / \mathrm{m}^{3}\right)$ and $c_{p a}=$ adsorption concentration.

Polymer adsorption is an important process that directly affects the permeability reduction and is related by the following equations [25-27].

$C_{a p}=C_{a p_{\max }}\left(\frac{b_{p} C_{P}}{1+b_{p} C_{P}}\right)$

$R_{k}=1+(R R F-1) \frac{C_{a p}}{C_{a p} \max }$

Where;

$C_{a p}=$ adsorbed polymer concentration $(\mathrm{kg} / \mathrm{kg}), C_{a p_{\text {max }}}=$ maximum adsorbed polymer concentration $(\mathrm{kg} / \mathrm{kg}), b_{p}=$ adsorption coefficient, $C_{P}=$ polymer concentration $\left(\mathrm{kg} / \mathrm{m}^{3}\right), R_{k}=$ permeability reduction factor and $\mathrm{RRF}=$ residual resistance factor.

The equation (5) above is analogous to rate growth saturation model. This therefore explains where there is high rate of polymer adsorption at the early stage of injection until an optimum rate is reached towards a longer injection period when high permeability streaks are more efficiently plugged off. 
The Influence of Permeability Variation in a Heterogeneous and Homogeneous Reservoir during Polymer Flooding

\subsection{Simulation Process}

This study uses a commercial reservoir simulator, ECLIPSE 100 to generate the synthetic reservoir model used in this study. The simulation option was based on a black oil model with in-situ fluid phases identified as water and oil phase. The reservoir model was calibrated to represent a heterogeneous system and the corresponding homogeneous counterpart was built by averaging the permeability of the heterogeneous system. The heterogeneous sample typically represents a local grid refinement of the coarse homogeneous Reservoir X-B as presented in Figure1. The solution scheme was IMPES implemented on a block centered rectangular reservoir. The reservoir grid parameters and well completion data are shown in Tables 1 and 2.

Table1. Reservoir Grid Definitions

\begin{tabular}{|l|l|l|}
\hline \multicolumn{1}{|c|}{ S/N } & \multicolumn{1}{|c|}{ Property } & Description/Unit \\
\hline Grid type & Cartesian (Block Centered) & $\mathrm{Ft}$ \\
\hline Grid Dimension & $10 \times 10 \mathrm{x} 1$ & \\
\hline Number of Cells & 100 & \\
\hline Permeability(Avg) & 25 & $\mathrm{Md}$ \\
\hline Porosity & 0.2 & Fraction \\
\hline Dx & 75 & $\mathrm{Ft}$ \\
\hline Dy & 75 & $\mathrm{Ft}$ \\
\hline Dz & 30 & $\mathrm{Ft}$ \\
\hline NTG Ratio & 1 & Dimensionless \\
\hline TOPS & 4000 & $\mathrm{Ft}$ \\
\hline
\end{tabular}

Table2. Well Specification and Completion

\begin{tabular}{|l|l|l|}
\hline \multicolumn{1}{|c|}{ Location/ Control Parameter } & \multicolumn{1}{c|}{ INJ1 } & \\
\hline i-location & 1 & 10 \\
\hline j-location & 1 & 10 \\
\hline k-upper & 1 & 1 \\
\hline k-lower & 1 & 1 \\
\hline Preferred Phase & Polymer & Oil \\
\hline Well type & Injector & Producer \\
\hline Well Control Mode & Liquid Rate/BHP & BHP \\
\hline Wellbore radius & $0.33 \mathrm{ft}$ & $0.33 \mathrm{ft}$ \\
\hline
\end{tabular}

\section{RESULTS AND DISCUSSION}

The Reservoir X considered in this work is a 2-D 10x10 uniform and isotropic grid system as shown in Figure 1 .Reservoir $\mathrm{X}-\mathrm{A}$ is a heterogeneous with permeabilities randomly distributed in both the $\mathrm{X}$ and Y plane while Reservoir X-B is a corresponding homogenous system with averaged permeability of $25 \mathrm{mD}$. Both cases were simulated at same reservoir conditions by considering a polymer injection option at a rate and concentration of 200STB/day and 50Lb/STB respectively. The entire field was analyzed at a time stepping of 10days over a 10years field life. To understand the influence of the reservoir heterogeneity on the predicted performance of the polymer flooding option diagonal grid cells and those of injection and production well vicinity was analyzed comparatively. The analyses were focused on the relative permeability to oil/water phase, the oil-water capillary pressure, polymer adsorption in the reservoir matrix, resulting permeability reduction, equivalent mixture viscosity, oil production potential and field pressure response.

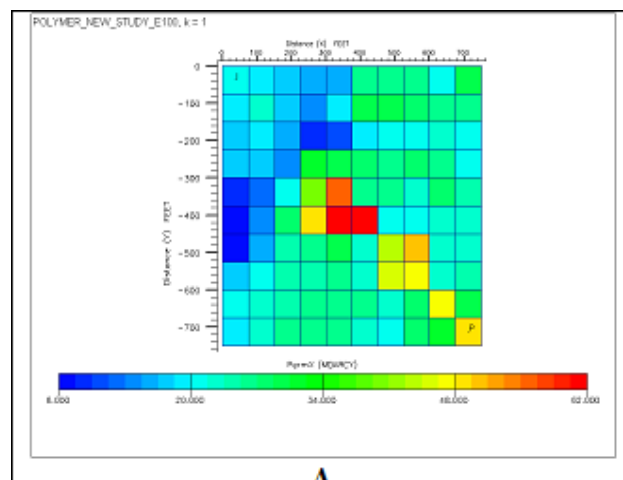

A

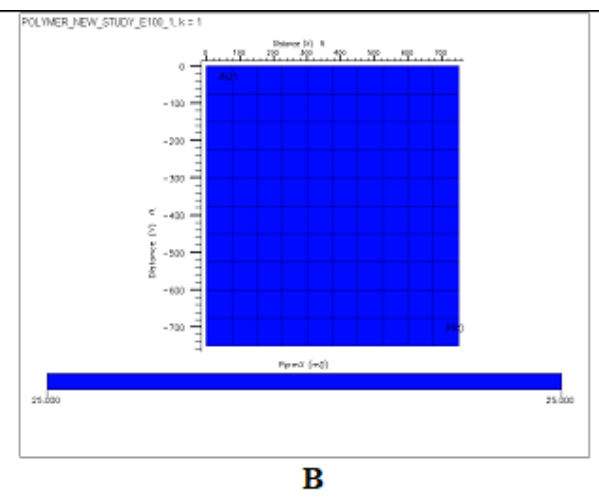

B

Figure1. Reservoir X Layout in 2-D (A=Heterogeneous System; B = Homogenous System) 


\subsection{Gridblock Phase Mobility}

The target for most polymer flooding operation is to reduce the mobility of the water phase thereby minimizing the tendency of viscous fingering and early water breakthrough that is observed as in increase in water cut. The result of Figure 2 compares the relative permeability to the oil phase (assuming a binary mixture of oil and water with polymer in solution) of the two reservoir systems. Since the viscosity of the fluids is constant, the phase relative permeability was used to assess the mobility of each distinct phase of the binary mixture.

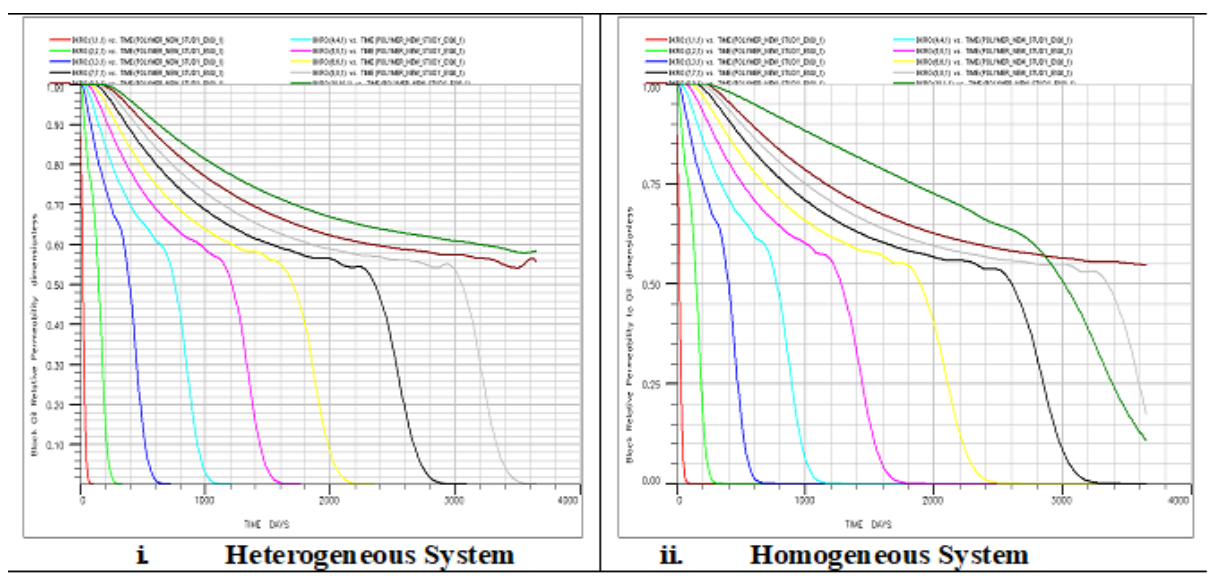

Figure2.Relative Permeability to Oil in the Main Diagonal Grids

There is fast reduction in the oil phase mobility in the heterogeneous system due to high permeable channels (with permeability above $25 \mathrm{md}$ ) where there is high chance of water phase by-passing the oil phase as shown in Figure 2. However, the mobility of the oil bank at the producer gridblock was relatively sustained because of low polymer injection rate that was insufficient to displace the oil banks at the $(10,10,1)$ grid cell. For the homogeneous system at a permeability of $25 \mathrm{md}$, there is water breakthrough through the producer which causes the mobility of the oil phase in the $(10,10,1)$ cell to drop earlier than nearest grids, $(8,8,1)$ and $(9,9,1)$. This indicates the oil phase by-passing by the water phase. The result presented in Figure 3 affirmed the former. Despite low mobility of oil phase in the producer grid, higher water phase mobility was attained much earlier in the heterogeneous system than the homogeneous system.
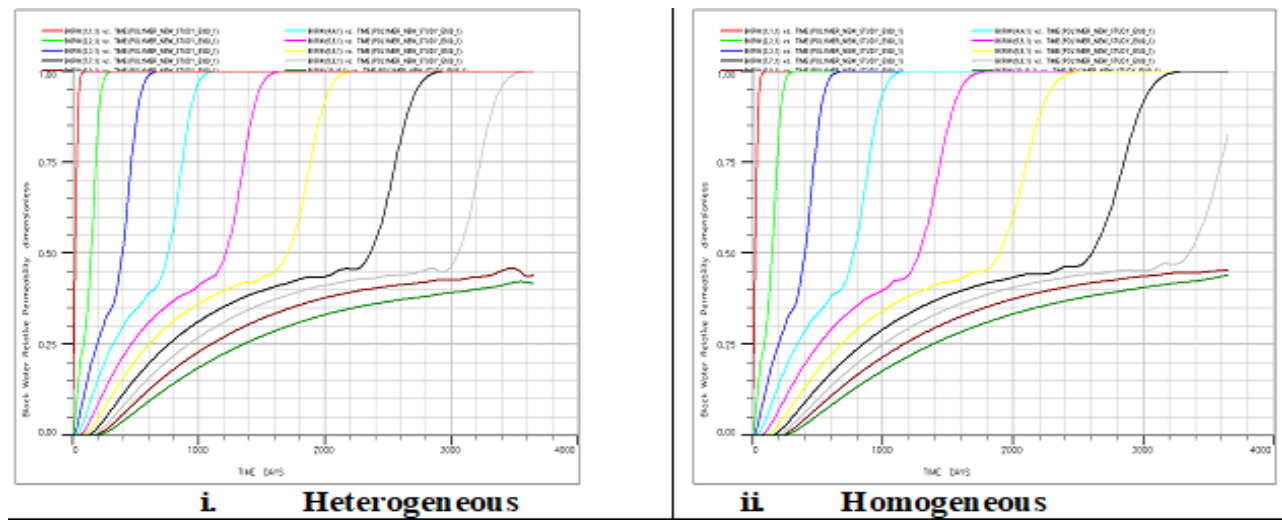

Figure3. Relative Permeability to Water in the Main Diagonal Grids

Due to area sweep effect, the major differences in fluid mobility occur in the production well area where high oil saturation exists (the un-swept oil banks).Figure 4 shows that the grid cells $(10,10,1)$ with high permeability streaks has the highest water phase mobility in the heterogeneous system whereas in the homogeneous system, the most remarkable difference was in the $(8,8,1)$ grid cell due its relatively far distance from the well. Hence, the grid cell $(8,8,1)$ has more effect of water during polymer injection than the other grids analyzed for both systems of the reservoir.

The effect of high permeability streaks was not so much felt in the grid cells at the center of the reservoir as illustrated in Figure 5. Hence, the similarity of the results obtained in both cases of the reservoir (Reservoir X-A and Reservoir X-B) showed that mobility control could be easier in 
reservoirs with high permeability streaks by considering a polymer flood option. However, the effect of drawdown in the wellbore vicinity creates a difficult scenario that may result to difficult mobility control which can be solve by increasing the polymer viscosity through either concentration or injection rate/pressure.

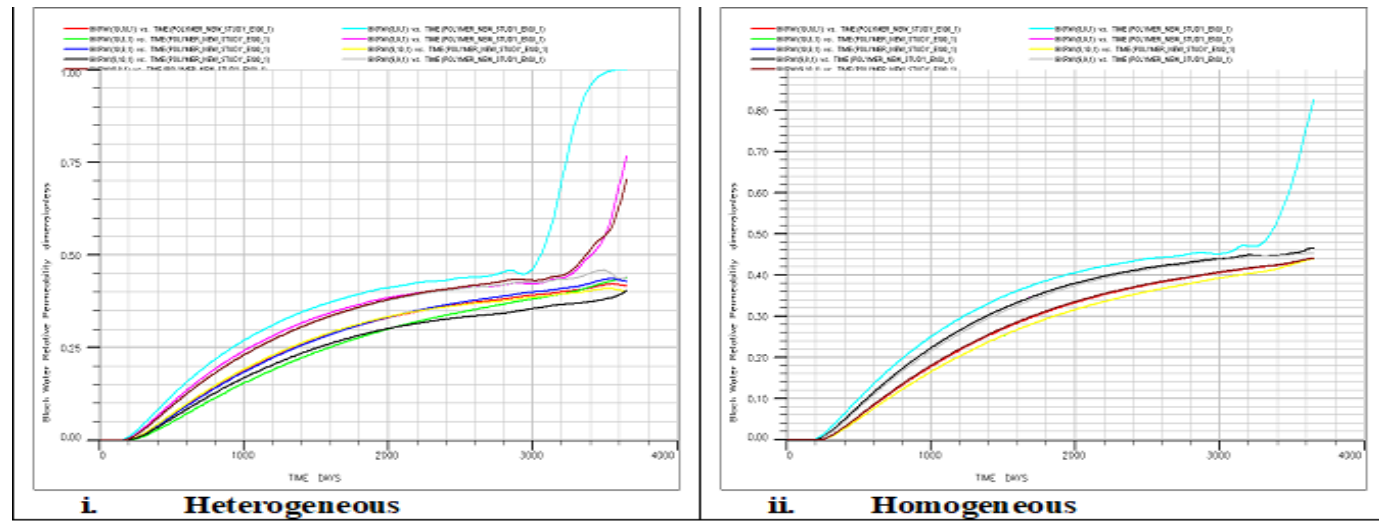

Figure4. Relative Permeability to Water in the Producer Cell and Nearest Neighboring Grids
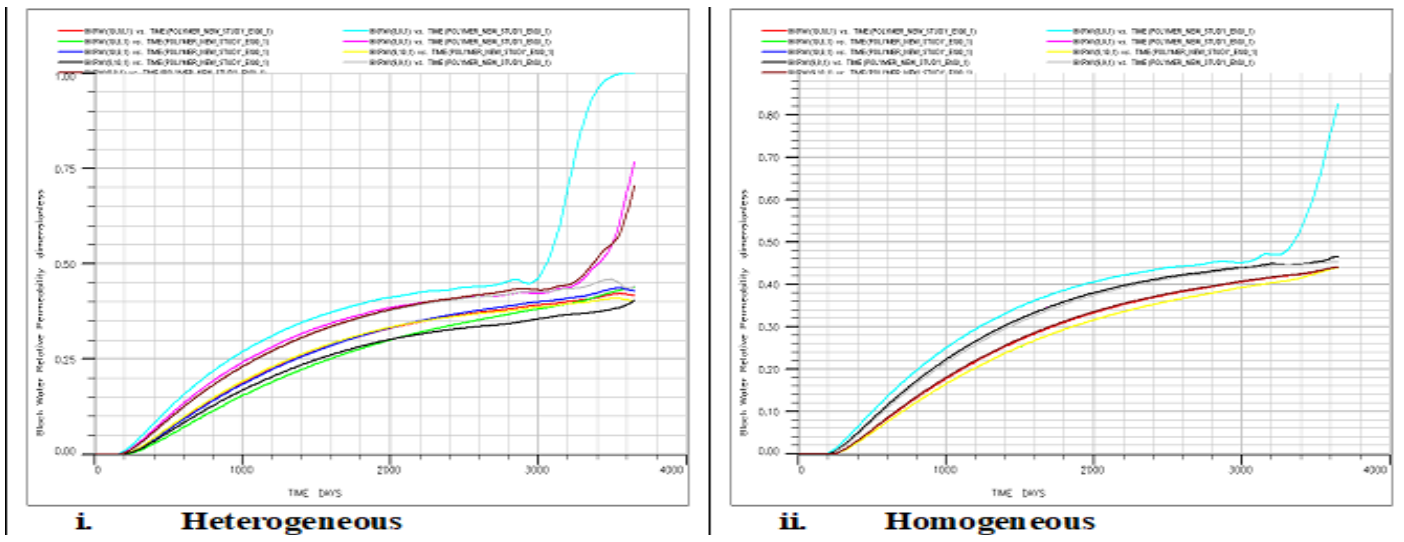

Figure5. Relative Permeability to Water in the Centre Grid Cells

\subsection{The Oil-Water Capillary Pressure}

From empirical relationships, the oil-water capillary pressure of a binary oil-water mixture is directly related to the phase saturation. In polymer flooding /water injection, the water saturation increases while those of the in-situ displaced fluid decreases due to withdrawal. The presence of high permeability channels in the reservoir system which results to higher water phase mobility increases water saturation in the affected grids.

There is higher oil-water capillary pressure in the grid cells nearest to the producer (where water breakthrough occurs) than those farthest as shown in Figure 6. However, only the producer grid and its immediate neighboring diagonal grids were affected in the homogeneous system. A clearer illustration of this process is shown for the grid cells of production well neighborhood in Figure 7.
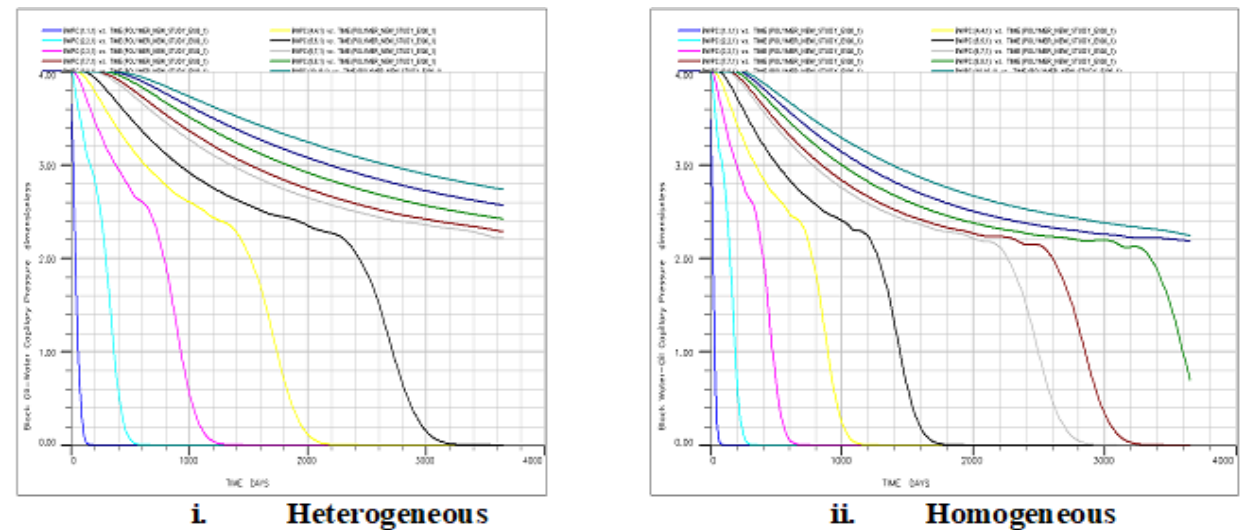

Figure6. Oil-Water Capillary Pressure of the Diagonal Grid Cells 

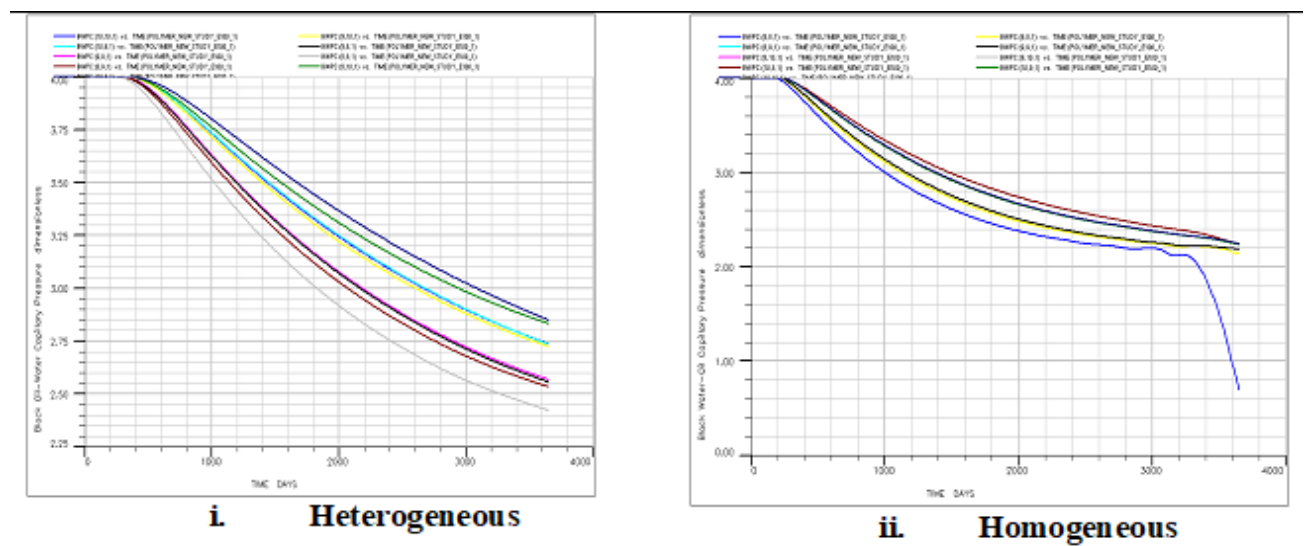

Figure7. Oil-Water Capillary Pressure of the Producer Grid and Immediate Neighboring Grid Cells

\subsection{Effect of Polymer Injection on Mixture Viscosity and Permeability Reduction}

One remarkable effect of most chemical EOR methods is increase in the flood water -polymer mixture viscosity. This eventually aids better in-situ fluid displacement through good mobility control. Reservoir heterogeneity does not have direct remarkable influence on the effective mixture viscosity (EMVIS) of the reservoir system as seen in Figure 8.

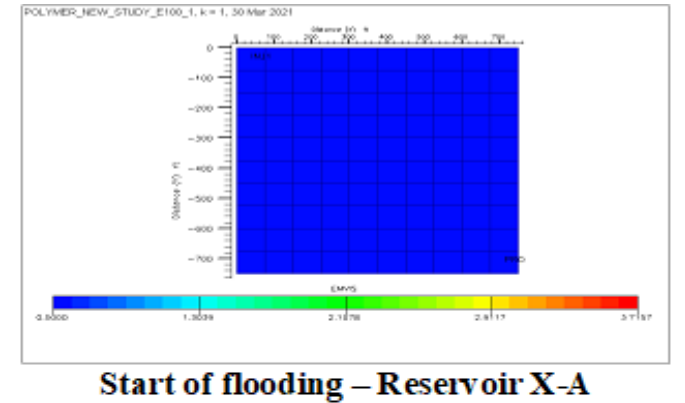

Start of flooding - Reserv oir X-A

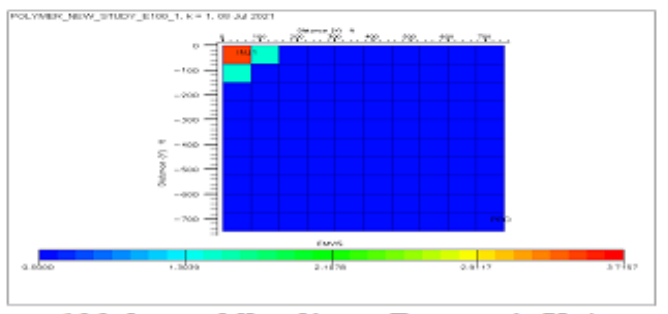

100 days of flooding - Reservoir X-A

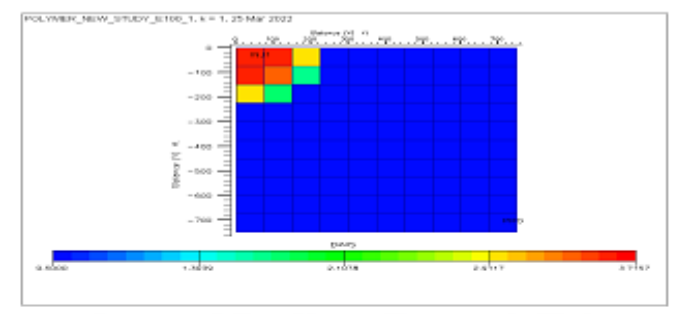

1 year of flooding - Reserv oir $\mathrm{X}-\mathrm{A}$

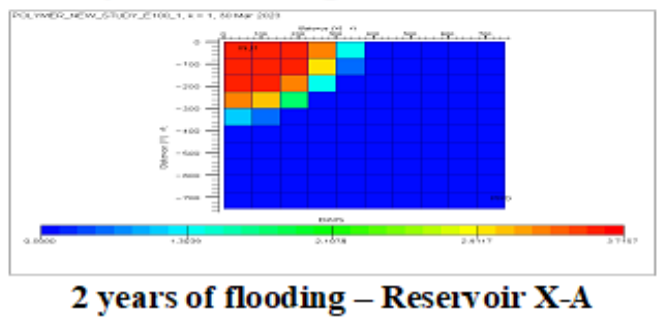

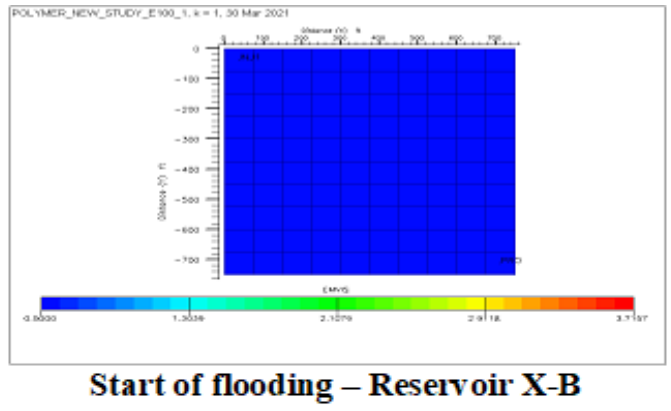

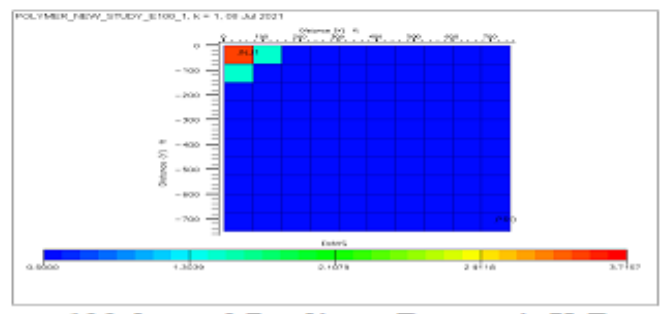

100 days of flooding - Reservoir X-B

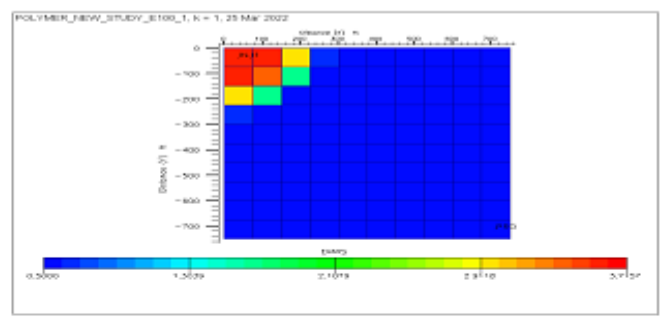

1 year of flooding - Reservoir X-B

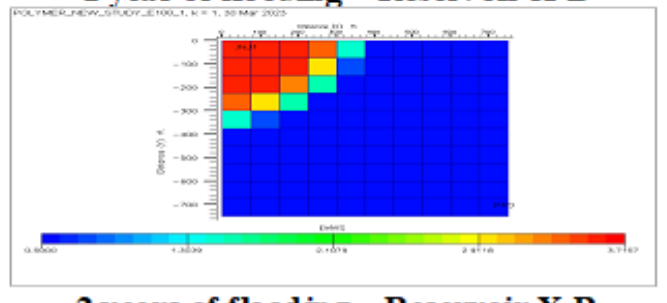

2 years of flooding - Reservoir X-B

Figure 8.Equivalent Mixture Viscosity at selected Timesteps 
Unlike as shown in Figure 8, the result presented in Figure 9 indicates the influence of reservoir permeability on permeability reduction coefficient. It shows a uniform progression in permeability reduction in the homogeneous system. The non-uniform progression in Reservoir X-A (heterogeneous) signifies the complexity of the reservoir heterogeneity existing in Reservoir X-A. However, the chart bar presented in Figure 9 shows a faster permeability reduction in the homogeneous system than the heterogeneous system. This is due to high permeable zones in the heterogeneous system that requires plugging for better mobility control.
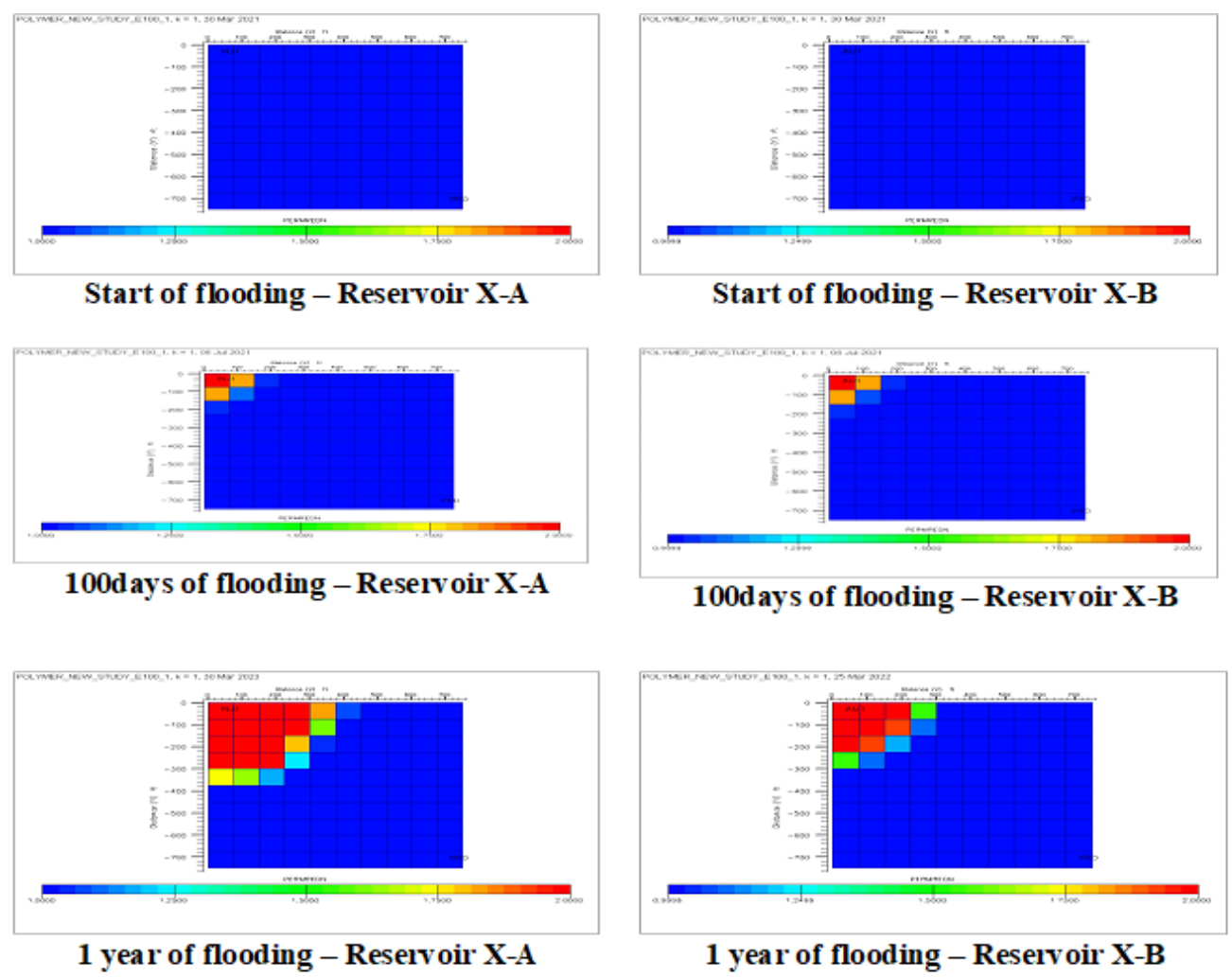

Figure9. Permeability Reduction Coefficient at selected Timesteps

The result of polymer adsorption due to permeability reduction in both reservoir systems is shown in Figure 10. It shows that the polymer adsorption rates in high permeable zones are quite lower than those of low permeable zone. This is attributed to the possibility of high oil saturation in these permeable streaks. The zero value at the producer grid blocks and the two nearest grids (in the heterogeneous system) affirmed the result. In addition, there is high water phase mobility in these regions due to the effect of the producer located at $(10,10,1)$ which is the same with the homogenous system. Minimum polymer adsorption was seen in gridblock $(9,9,1)$ while that of the producer grid was zero (case of heterogeneous system) caused by the combined effect of pressure drawdown and increase in water phase mobility.

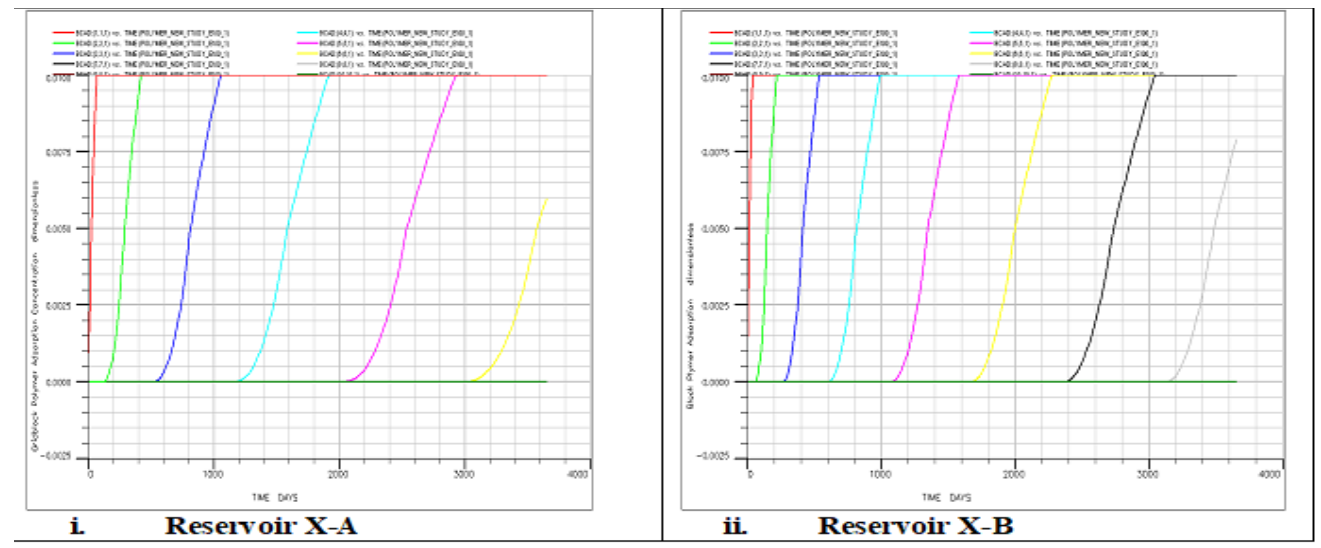

Figure10. Grid Block Polymer Adsorption 


\subsection{The Influence of Reservoir Heterogeneity on Field Pressure and Flowing Bottomhole Pressure}

Figure 11 and 12 shows the influence of reservoir heterogeneity on field pressure and well bottomhole pressure (WBHP) respectively. The heterogeneous reservoir has the highest pressure decline than the homogeneous system. There is a sharp increment in pressure that was succeeded by a decline in both reservoir systems. The future trend indicates a rise in pressure up to initial condition for the homogeneous case and relatively stabilized pressure curve for the heterogeneous system. Similarly, the flowing bottomhole pressure is higher for the homogeneous system than the heterogeneous system. There will be more continual WBHP increment in the homogeneous Reservoir X-B than the heterogeneous system.

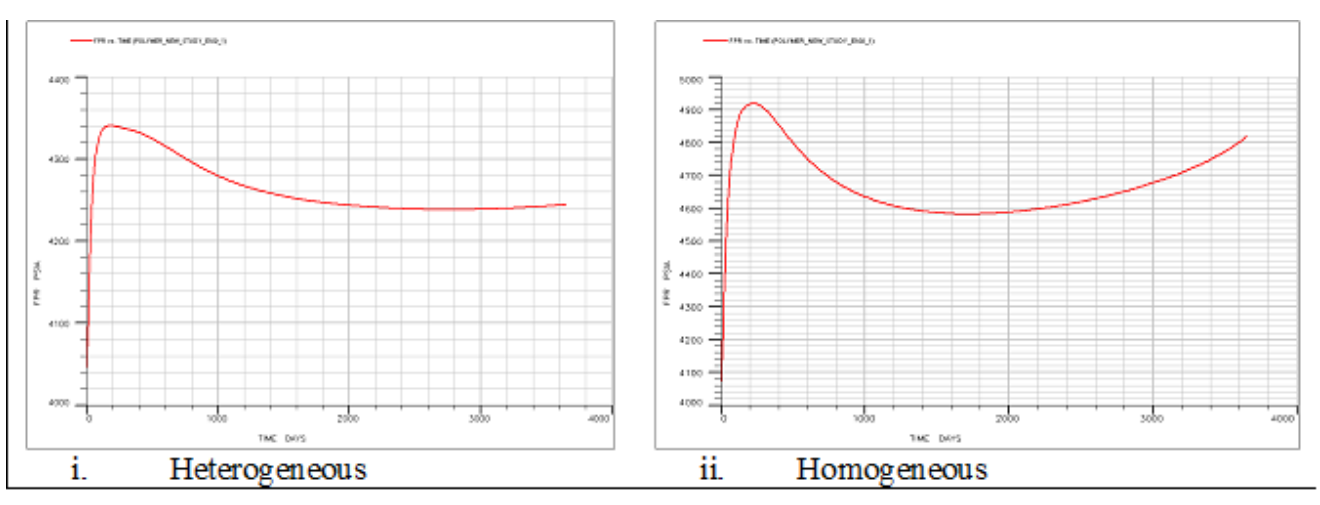

Figure11. Field Pressure Profile

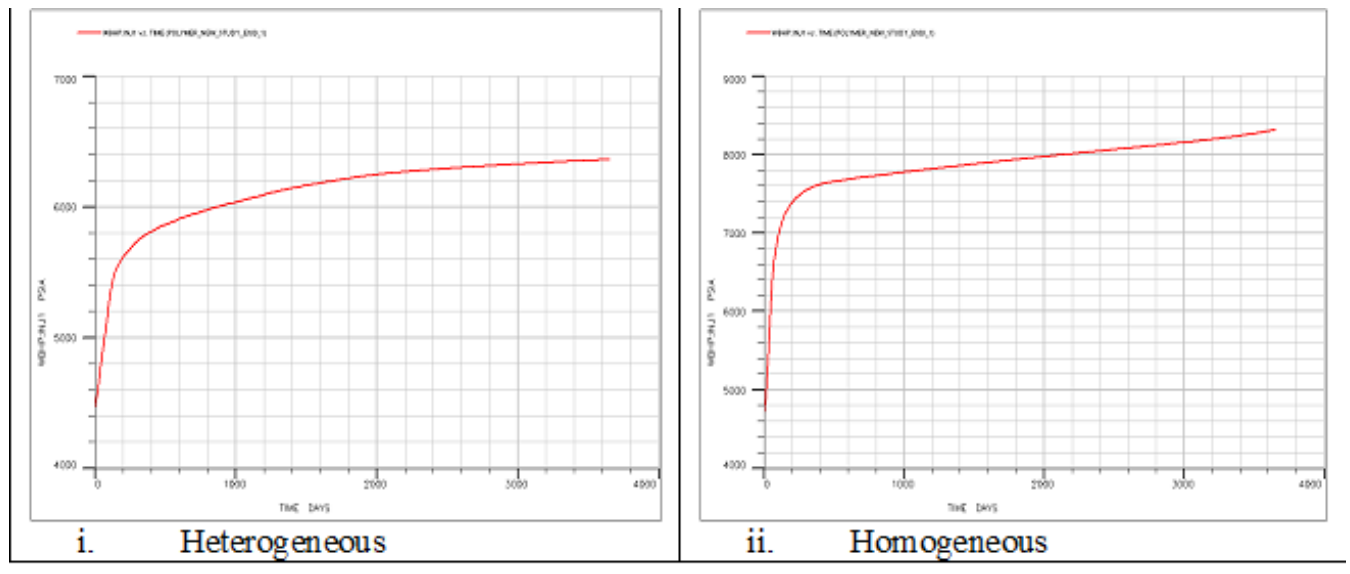

Figure12. Flowing Bottomhole Pressure

\subsection{Field Oil Production Rate for both system}

The homogenous system has better oil production rate than the heterogeneous system resulting from lower pressure profile of the heterogeneous system and the combined effect of mobility challenges posed by the extremely highly permeable zones as presented in Figure 13.
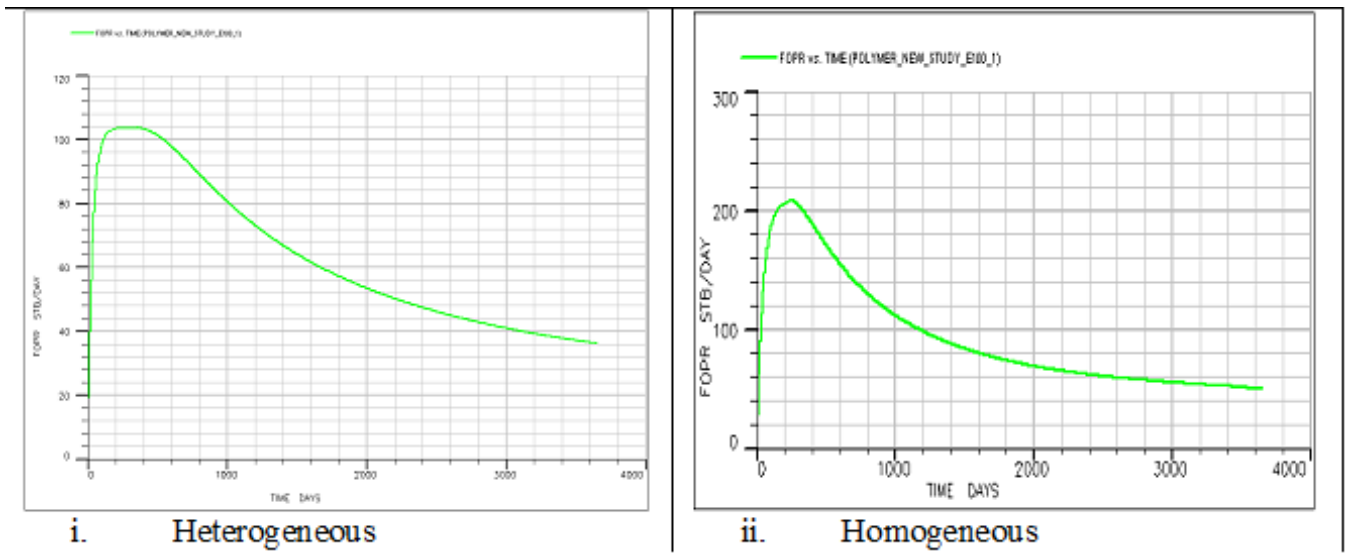

Figure13. Field Oil Production Rate 


\section{CONCLUSION}

This study has investigated the impact of permeability variation in heterogeneous and homogeneous system during polymer flooding. Two synthetic reservoirs have been thoroughly analyzed - Reservoir X-A (heterogeneous) and Reservoir X-B (homogeneous) systems.

The following conclusions were drawn;

- Reservoir heterogeneity remarkably impacts fluid mobility. The extent of this impact is directly related to the degree of heterogeneity of the system.

- The presence of high permeability streaks (permeable channels) is more pronounced in the production well vicinity. It is therefore relatively easier to manage when located far from the producer using polymer flooding option

- Reservoir heterogeneity impacts fluid saturation distribution which changes oil-water capillary pressure.

- High reservoir permeability causes a reduction in polymer adsorption

- Reservoir heterogeneity does not have direct effect on the mixture viscosity. However, this changes as polymer front advances closer to the producer

- Polymer flooding causes a remarkable permeability reduction which makes it an excellent option for plugging off thief zones (high permeable streaks.

\section{REFERENCES}

[1] Bane, R., Parker, R., Storbeck, W. G., \& Sunde, R. L. (1994). Reservoir Management of the Fullerton Clearfork unit. Proceedings of the Permlan Basin Oil and Gas Recovery Conference (pp.16-18). Society of Petroleum Engineers.

[2] Germanovich, L., Hurt, R., Ayoub, J., Siebrits, E., Norman, D., Ispas, I., \& Montgomery, C. T. (2012). Experimental Study of Hydraulic Fracturing in Unconsolidated Materials. SPE International Symposium and Exhibition on Formation Damage Control. SPE Onepetro

[3] Zhang, P., Pickup, G. E., \& Christie, M. A. (2008). A New Practical Method for Upscaling in Highly Heterogeneous Reservoir Models. SPE Journal, 68-76.

[4] Feng, Q., Wang, S., Zhang, W., Song, Y., \& Song, S. (2013). Characterization of Highly-Permeablility Streak in Mature Waterflooding Reservoirs Using Pressure Transient Analysis. Journal of Petroleum Science and Engineering, 55-65.

[5] Wang, J., Zhu, W., Shi, C., Wang, J., \& Liu, Y. (2020). Assesment of Polymer Flooding Effects on the Recovery of Heterogeneous Thick Reservoirs with Dominant Channel . Journal of Petroleum Exploration and Production Technology, 1533-1538.

[6] Deng, S., Lu, W., Liu, Q., Leng, Z. P., Liu, H. H., Gu, H., Lu, X. (2014). Research on Displacement Mechanism in Conglomerate Using CT Scanning Method. Petroleum Exploration and Development, 365-370.

[7] Dupas, A., Henaut, I., Rousseau, D., Poulain, P., Tabary, R., Argillier, J. F., \& Aubry, T. (2013). Impact of Polymer Mechanical Degradation on Shear and Extensional Viscosities: toward better injectivity forecasts in polymer flooding operations. SPE International Symposium on Oilfield Chemistry.

[8] Karmal, M., Sorop, T., Postif, S., \& Van-den-Hoek, P. J. (2015). Review on Polymer Flooding: Rheology, Adsorption, Stability, and Field Applications of Various Polymer Systems. Polym Rev, 491-530

[9] Mahran, S., Attia, A., \& Saha, B. (2018). A Review on Polymer Flooding in Ehanced Oil Recovery under Harsh Conditions. The 11th International Sustainable Energy and Environmental Protection Conference. Paisley, Scotland.

[10] Riahinezhad, M., Romero-Zeron, L., McManus, N., \& Penlidis, A. (2017). Evaluating the Performance of Tailor-made Water-Soluble Copolymers for Ehnaced Oil Recovery Polymerb Flooding Applications. Fuel, $269-278$.

[11] Gbadamosi, A. O., Junin, R., Manan, M., Yekeen, N., Agi, A., \& Oseh, J. O. (2018). Recent Advances and Prospects in Polymeric Nanofluids Application for Ehanced Oil Recovery. J. Ind. Eng. Chem.

[12]Ekkawong, P., Han, J., Olalotti-Lawal, F., \& Datta-Gupta, A. (2017). Multiobjective Design and Optimization of Polymer Flood Performance. J. Pet. Sci. Eng, 153, 47-58.

[13] Algharaib, M., Alajmi, A., \& Gharbi, R. (2014). Improving Polymer Flood Performance in High Salinity Reservoirs. J. Pet. Sci. Eng, 115, 17-23. 
[14] Choi, J., Ka, D., Chung, T., Jung, J., Koo, G., Uhm, T., Jung, H. T. (2015). Evaluation of Highly Stable Ultrahigh-Molecular-Weight Partially Hydrolyzed Polyacrylamide for Ehanced Oil Recovery. Macromol. Res, 23, 518-524.

[15] Cai, S., He, X., Liu, K., Zhang, R., \& Chen, L. (2015). Interraction between HPAM and Urea in Aqueous Solution and Rheological Properties. Iran. Polym. J, 24, 663-670.

[16] Hatzignatiou, D. G., Moradi, H., \& Stavland, A. (2015). Polymer Flow through Water - and Oil-Wet Porous Media. J. Hydrodyn. Ser. B, 27, 748-762

[17]Zhao, G., Fang, J., Gao, B., Wang, Y., Chen, A., Wen, D., \& Dal, C. (2015). Study and Application of the Adsorption of Anionic and Cationic Polymer. Oilfield Chem., 32, 62-66.

[18] De-Oliveira, L. F., Schiozer, D. J., \& Delshad, M. (2016). Impacts of Polymer Properties on Field Indicators of Reservoir Development Projects. J. Pet. Sci. Eng, 147, 346-355.

[19] Sheng, J. J., Leonhardt, B., \& Azri, N. (2015). Status of Polymer-Flooding Technology. J. Can. Pet. Technol, 54, 116-126.

[20] Wei, B., Romero-Zeron, L., \& Rodrigue, D. (2014). Oil displacement mechanisms of viscoelastic polymers in enhanced oil recovery (EOR): a review. Journal of Petroleum Exploration and Production Technology, 4, $113-121$.

[21] Sorbie, K. (1991). Polymer-Improved Oil Recovery. Glasgow and London: Blacckie and Son Ltd.

[22] Ibiam, E., Geiger, S., Demyanov, V., \& Arnold, D. (2020). Optimisation of Polymer Flooding in a Heterogeneius Reservoir Consideriing Geological and History Matching Uncertainties. SPE Onepetro

[23] Ibiam, E., Sebastian, G., Almaqbali, A., Demyanov, V., \& Amold, D. (2018). Numerical Simulation of Polymer Flooding in a Heterogeneous Reservpoir Contrained versus Unconstrained Optimization. SPE Onepetro

[24] Xin, X., Yu, G., Chen, Z., Wu, K., \& Dong, X. a. (2018). Effect of Polymer Degradation on Polymer Flooding in Heterogeneous Reservoirs. Polymers.

[25] Adamson, A., \& Gast, A. P. (1997). Physical Chemistry of Surfaces. New York, USA: John Wiley \& Sons.

[26] Chaudhuri, A., \& Vishnudas, R. (2018). A Systematic Numerical Modeling Study of Various Polymer Injection Fuel, 232, 431-443.

[27] Bao, K., Lie, K. A., Moyner, O., \& Liu, M. (2017). Fully implicit simulation of polymer flooding with MRST. Comput. Geosci, 21, 1219-1244.

Citation: Bright Bariakpoa Kinate, et.al (2021). "The Influence of Permeability Variation in a Heterogeneous and Homogeneous Reservoir during Polymer Flooding”, International Journal of Petroleum and Petrochemical Engineering (IJPPE), 7(1), pp.1-10. DOI: https://doi.org/10.20431/2454-7980.0701001

Copyright: () 2021 Authors, This is an open-access article distributed under the terms of the Creative Commons Attribution License, which permits unrestricted use, distribution, and reproduction in any medium, provided the original author and source are credited. 